\title{
SUBJETIVIDADE E ENFRENTAMENTO DA MORTE: CONSTRUINDO GESTÃO DE PESSOAS NA COTIDIANIDADE ${ }^{1}$
}

\author{
Caroline Bastos Capaverde ${ }^{2}$ \\ Livia Pedersen de Oliveira ${ }^{3}$ \\ Angela Beatriz Busato Scheffer ${ }^{4}$
}

http://dx.doi.org/10.1590/1413-2311.171.63740

\begin{abstract}
RESUMO
O presente estudo objetivou compreender como são pensadas e construídas práticas de trabalho e de gestão de pessoas na cotidianidade de um local onde o trabalho exige enfrentamento com a morte. Esse é um estudo qualitativo. Foi realizado o acompanhamento da rotina de 4 agentes funerários, 1 diretor de plantão, 1 gerente administrativo e 1 maquiadora necrotérica em seu contexto de trabalho em uma empresa funerária de pequeno porte em Porto Alegre. Para a coleta de dados foram utilizadas técnicas etnográficas (CAVEDON, 2003), sendo a interpretação realizada por meio de análise de conteúdo (MINAYO, 2010). Os achados foram agrupados em quatro categorias que, entende-se, integram o processo de subjetivação do fazer/saber diante da morte: 1) redimensionando as certezas; 2) os saberes no/do trabalho frente à ressignificação da morte; 3) ser trabalhador atravessado pela representação da morte em sociedade; e 4) gestão se configurando no contexto da morte. Vimos que esses profissionais criam, reinventam suas maneiras de fazer, a partir de um processo de ressignificar e naturalizar a morte, sendo o ambiente organizacional, em consonância com Certeau (2008), um espaço onde trabalhadores fazem a gestão do seu cotidiano e de si mesmos com seus próprios significados.
\end{abstract}

Palavras-Chave: Gestão em Pequenas Empresas. Funerárias. Subjetividade. Cotidiano. Morte.

\section{SUBJECTIVITYAND COPING WITH DEATH: BUILDING PEOPLE MANAGEMENT IN DAILY LIFE}

\begin{abstract}
This study aimed to understand how work practices and people management are designed and built in daily life, in a place whose work requires coping with death. This is a qualitative study which followed the routine of 4 morticians, 1 on-call manager, 1 administrative manager and 1 mortuary make-up artist in their working environment, a small funeral

\footnotetext{
${ }^{1}$ Recebido em 04/04/2016; aprovado em 26/06/2017.

${ }^{2}$ Universidade Federal do Rio Grande do Sul - ccapaverde@gmail.com.

${ }^{3}$ Universidade Federal do Rio Grande do Sul - lívia.pedersen@ gmail.com.

${ }^{4}$ Universidade Federal do Rio Grande do Sul.
}

REAd | Porto Alegre - Vol. 23 - No Especial - Dezembro 2017 - p. 188-209
\end{abstract}


company in Porto Alegre. Data was collected using ethnographic techniques (CAVEDON, 2003) and the interpretation performed by content analysis (MINAYO, 2010). The findings were grouped into four categories understood as part of the process of subjectivation of practice/ knowledge in face of death: 1) resizing the certainties; 2) knowledge at/about the work in face of death reframing; 3) being a worker shaped by the representation of death in society; and 4) management being construed in the context of death. We have seen that these professionals create and reinvent their practices, starting from a process of reframing and naturalizing death. The organizational environment, in line with Certeau (2008), is a space where workers use their own meanings in the management of themselves and their daily life.

Keywords: Small Business Management. Funeral Homes. Subjectivity. Daily Life. Death.

\title{
LA SUBJETIVIDAD Y EL ENFRENTAMIENTO DE LA MUERTE: CONSTRUYENDO LA GESTIÓN DE PERSONAS EN EL COTIDIANO
}

\begin{abstract}
RESUMEN
El presente estudio tuvo como objetivo comprender cómo, en un lugar donde el trabajo requiere hacer frente a la muerte, se diseñaron y construyeron en la vida diaria, las prácticas de trabajo y la gestión de personas. Se trata de un estudio cualitativo, en que se realizó el seguimiento de rutina de cuatro agentes funerarios, un director de guardia, un gerente administrativo y maquilladora de muertos en su entorno de trabajo, una pequeña empresa funeraria en Porto Alegre. Para recopilar los datos, se utilizaron técnicas etnográficas (CAVEDON, 2003), y la interpretación se realizó a través del análisis de contenido (MINAYO, 2010). Los resultados se agruparon en cuatro categorías que forman parte del proceso de subjetivación del hacer/saber ante la muerte: redimensionando las certidumbres 1) cambio de tamaño; 2) los saberes en el/del trabajo ante la resignificación de la muerte; 3) ser un trabajador traspasado por la representación de la muerte en la sociedad; y 4) la gestión configurándose en el contexto de la muerte. Hemos visto que esos profesionales crean, reinventan sus formas de hacer a partir de un proceso de resignificación y naturalización de la muerte, en que el entorno de la organización, de acuerdo con Certeau (2008), es un espacio donde los trabajadores hacen la gestión de su vida diaria y de si mismos con sus propios significados.
\end{abstract}

Palabras clave: Gestión en Pequeñas Empresas. Funeraria. Subjetividad. Cotidiano. Muerte.

\section{INTRODUÇÃO}

A gestão pode ser entendida como uma prática social, espaço onde diversas "maneiras de fazer ou estilos de ação" são reapropriadas a partir de uma multiplicidade de táticas (CERTEAU, 2008, p.41). Assim compreendendo, valoriza-se o que é vivido no cotidiano: solidariedades, relações de interesses convergentes e divergentes, saberes/fazeres e entendimentos práticos, lutas, significados construídos pelos próprios sujeitos, aspectos que

REAd | Porto Alegre - Vol. 23 - No Especial - Dezembro 2017 - p. 188-209 
durante um bom tempo foram desvalorizados nos estudos de gestão, os quais priorizaram aspectos objetivos, racionais, unificadores.

Entende-se que tais dimensões fazem parte de um universo de organizações e vão constituindo a própria gestão, enquanto processo interativo que inclui a gestão de pessoas. Considerar que para se compreender a gestão de pessoas é preciso uma noção de "subjetividade", mas não somente como um "eu", e sim uma intersubjetividade, uns "nós" fundamental (DAVEL; VERGARA, 2001, p.47), é ver a gestão não como atributo exclusivo do gestor, mas uma construção social, um espaço de significados atribuídos na cotidianidade.

Com foco nesses aspectos constituídos no cotidiano, julgou-se pertinente olhar para a gestão de pessoas em uma pequena empresa, por ser um espaço dinâmico e por suas especificidades de gestão (LEONE, 1999). Para esse estudo, optou-se por investigar o ramo funerário, que envolve atividade profissional alicerçada em uma rotina que exige a convivência com a morte e o morrer. Este ramo dedica-se ao cuidado diante da perda, e se ocupa de todos os trâmites, desde a morte até o enterro/cremação.

Morin (1988) coloca que não há praticamente nenhum grupo, por mais primitivo que seja, que abandone seus mortos ou que o abandone sem ritos. Mesmo assim, como destaca Cavedon (2011), os estudos acadêmicos que contemplam a morte como temática de reflexão não são recorrentes, sendo relevante elucidar determinados aspectos, na medida em que eles serão reveladores de práticas no âmbito do espaço organizacional, acionadas com o intuito de tornar viável o enfrentamento de um cotidiano permeado de emoções, sentimentos.

Assim, esse trabalho objetivou compreender como, em local cujo trabalho exige enfrentamento com a morte, são pensadas e construídas práticas de trabalho e gestão de pessoas. Julgou-se importante entender de que forma estas práticas e a própria gestão de pessoas são permeadas pelo sentido que o trabalhador dá à morte.

A seguir, o artigo está estruturado da seguinte forma: revisão da literatura, campo de estudo, as funerárias, o percurso metodológico, seguido das reflexões acerca do tema da morte no campo de trabalho, apresentando assim os achados e a discussão do estudo, seguido das considerações finais.

\section{REVISÃO DA LITERATURA}

\subsection{AGENTES FUNERÁRIOS E A MORTE}

REAd | Porto Alegre - Vol. 23 - No Especial - Dezembro 2017 - p. 188-209 
Ao nascermos iniciamos nosso processo de envelhecimento, ou seja, é um processo natural e inevitável que faz parte da vida. Surpreendentemente, na contramão desse movimento, desenvolvemos uma aviltante negação acerca da finitude. Como não sabemos o momento em que iremos morrer, essa incerteza, não raro, promove no homem uma aparente necessidade de distanciamento de pensar e de conviver com a morte.

Vigotski (1996, p. 265) afirma que a própria ciência assimilou muito bem o conceito de vida, mas não conseguiu explicar o de morte: "A morte é interpretada somente como uma contraposição contraditória da vida, como a ausência da vida, em suma, como o não-ser. Mas a morte é um fato que tem também seu significado positivo, é um aspecto particular do ser e não só do não-ser; é um certo algo e não o completo nada".

Em outro estudo, o qual recupera historicamente as representações sobre a morte e o morrer, Caputo (2008) caracteriza a morte pelo mistério, pela incerteza e, consequentemente, pelo medo daquilo que não se conhece, pois os que a experimentaram não tiveram chances de relatá-la aos que aqui ficaram. Todos esses atributos da morte desafiaram e desafiam as mais distintas culturas, as quais buscaram respostas nos mitos, na filosofia, na arte e nas religiões, buscando assim pontes que tornassem compreensível o desconhecido a fim de remediar a angústia gerada pela morte. A morte, então, tornou-se um tabu na vida em sociedade.

$\mathrm{Na}$ esteira desse pensamento, recupera-se Morin (1970), em O Homem e a Morte. Na obra, o autor apresenta um importante questionamento - da relação do homem com a morte para o percurso reflexivo proposto nesse estudo. Um dos aspectos abordados pelo autor é a relação do homem com o luto, o qual exprime socialmente a inadaptação à morte, mas, ao mesmo tempo, o luto aparece também como um processo social de adaptação que tende a fechar a ferida dos indivíduos sobreviventes.

Além do luto, Morin (1970) apresenta os rituais pós-morte. Ele afirma que o homem é a única espécie que acredita na sobrevivência após a morte, e por isso, acompanha a morte com um ritual funerário e as sepulturas são elementos característicos fundamentais da morte humana.

As empresas que organizam esse trabalho integram o ramo funerário. Esse segmento se dedica ao cuidado diante da perda, ocupa-se de todos os trâmites - resgate, cuidado e preparação do corpo desde a morte até o enterro/cremação. Segundo, as orientações técnicas para as funerárias (ANVISA, 2009), são considerados estabelecimentos funerários e congêneres, as empresas públicas ou privadas que desenvolvam qualquer uma das seguintes atividades:

(a) remoção de Restos Mortais Humanos - medidas e procedimentos relacionados à remoção REAd | Porto Alegre - Vol. 23 - No Especial - Dezembro 2017 - p. 188-209 
de restos mortais humanos, em urna funerária, bandeja ou embalagem específica, desde o local do óbito até o Estabelecimento Funerário, adotando todos os cuidados de biossegurança necessários para se evitar a contaminação de pessoas e/ou do ambiente;

(b) higienização de restos mortais humanos - medidas e procedimentos utilizados para limpeza e antissepsia de restos mortais humanos, com o objetivo de prepará-los para procedimentos de conservação, inumação ou outra forma de destino;

(c) tamponamento de restos mortais humanos - uso de tampões para vedação dos orifícios do cadáver;

(d) conservação de restos mortais humanos - empregos de técnicas, através das quais os restos mortais humanos são submetidos a tratamentos químicos, com vistas a manterem-se conservados por tempo total e permanente ou previsto, quais sejam, o embalsamamento e a formolização, respectivamente;

(e) tanatopraxia - emprego de técnicas que visam à conservação de restos mortais humanos, reconstrução de partes do corpo e embelezamento por necromaquiagem;

(f) ornamentação de urnas funerárias - colocação de flores, véus e adornos decorativos e religiosos, conforme tradições e orientação religiosa;

(g) necromaquiagem - execução de maquiagem de cadáveres, com aplicação de cosméticos específicos;

(h) comércio de artigos funerários - exposição para venda de artigos funerários, tais como urnas funerárias (caixões), objetos decorativos e religiosos;

(i) velório: honras fúnebres, conforme tradições e orientação religiosa, ato de velar cadáveres;

(j) translado de restos mortais humanos - todas as medidas relacionadas ao transporte de restos mortais humanos, em urna funerária, inclusive as referentes à sua armazenagem ou guarda temporária até sua destinação final.

Nesse escopo, para realizar essas tarefas, é necessário o grupo dos trabalhadores funerários, organizado nas seguintes categorias funcionais: maquiadores necrotéricos, motoristas, agentes funerários, recepcionistas, entre outros. Os profissionais que decidem trabalhar nas agências funerárias precisam desenvolver processos de naturalização e subjetivação diante do trabalho/morte para realizar o seu ofício de forma objetiva e profissional.

Com relação ao mercado de trabalho, em outro estudo que aborda o tema das agências funerárias, Herval e Menezes (2008) apontaram que, em sua maioria, é formado por funcionários que não concluíram o ensino fundamental, mas também há universitários 
(principalmente os que fizeram cursos de Administração de Empresas e Secretariado) e especialistas no setor, como é o caso dos técnicos de tanatopraxia (procedimento de preparação do cadáver para o funeral que inclui reconstituição do corpo e lavagem das vísceras com antibactericida).

É no contexto desse trabalho, com suas características específicas, e junto com seus profissionais, que acontece a gestão de pessoas nessas empresas. Assim, como já destacado, é nesse contexto de trabalho e de enfrentamento com a morte, que são pensadas e construídas práticas de trabalho e de gestão de pessoas, o que será discutido nas próximas seções.

\subsection{GESTÃO DE PESSOAS EM PEQUENAS EMPRESAS FUNERÁRIAS: UMA PRÁTICA CONSTRUÍDA NA COTIDIANIDADE}

Gerir pessoas é um constante desafio nas organizações, seja pelos desafios ambientais que envolvem sempre novas soluções em vista da sobrevivência ou principalmente do crescimento das organizações, seja pela complexidade dos relacionamentos entre diferentes pessoas, equipes, somadas a expectativas de clientes, etc. Por gestão de pessoas entende-se os esforços e decisões, ou conjunto de políticas e práticas, direcionadas à construção de desempenho individual e organizacional, existindo enquanto processo inevitável em todos os tipos de empresas e tendo implicação na gestão de modo geral. Envolve, assim, decisões que implicam na adoção de estilos de atuação de gestores até mesmo orientações fundamentais para o desempenho individual e coletivo.

Assim, todos os tipos de empresas desenvolvem gestão de pessoas, embora, de modo geral, a literatura gerencial centre suas discussões em teorias, modelos, ferramentas e técnicas aplicadas às grandes empresas. Entretanto, como apontam Leone (1999), Shaharin (2012) e Sparrow (2006), dentre outros, tais teorias não dão conta da dimensão particular de pequenas e médias empresas, por sua heterogeneidade e ambiguidades próprias.

Segundo Leone (1999), as pequenas e médias empresas podem ser estudadas a partir de suas especificidades. A autora ressalta que entre as características específicas das pequenas empresas podemos destacar sua estrutura mais centralizada, com as atividades distribuídas entre poucas funções administrativas, ação guiada pela sensibilidade do gestor, com processos de planejamento e controle pouco formalizados e quantificados, estratégia intuitiva, com uma grande aproximação entre o proprietário e seus funcionários e entre proprietário e seus clientes, e tomada de decisão baseada na experiência. Deste modo, entende-se que na gestão 
em pequenas empresas existe muito conhecimento adquirido pela prática, pelos fazeres cotidianos, conhecimentos esses que vão moldando inclusive a forma de atuar no mercado no qual estão inseridas, aspectos que são fundamentais de serem considerados.

No contexto brasileiro, a maior parte de nossas organizações são pequenas e médias empresas, geralmente de origem familiar, nas quais os gestores são demandados para dar conta de uma série de desafios em seus contextos específicos, envolvendo gestão, o que inclui a gestão de pessoas. Por suas características, nas relações entre as pessoas e nas relações de trabalho, são postos em cena laços familiares ou mesmo laços afetivos adquiridos, emoções, saberes e entendimentos práticos, ambivalências, valores, que vão constituindo-se, em lógicas diferentes dessas que são apresentadas nos modelos baseados nas grandes corporações. Práticas de gestão de pessoas são, então, construídas e significadas na cotidianidade, o que exige um olhar, como apontam Nguyen e Bryant (2004), não somente para as práticas que lá existem, mas também para a forma como estas se constituem em seus contextos.

Nesse sentido, emerge a ideia de pesquisar os "fazeres/saberes" na gestão "no/do/com" o cotidiano em organizações. As pesquisas "no/do/com" o cotidiano questionam a cisão entre o saber formal e os saberes cotidianos, a teoria e a prática, bem como o pensar e o fazer (JUNQUILHO; ALMEIDA; SILVA, 2012). Gestão de pessoas seria entendida como um conjunto de saberes e "fazeres com", trazidos a partir de vivências e produzidos no dia-a-dia, a partir de diferentes contextos, que acabam configurando os modos de trabalhar em organizações.

Assim abordando, procura-se explorar como as práticas de gestão de pessoas vão sendo pensadas, praticadas, formuladas, ajustadas e configuradas nessas vivências, nas interações, podendo até serem formalizadas com o tempo. É procurar dar conta da complexidade do cotidiano das empresas, de sua dinâmica, de suas contradições. Como colocam Edwards e Wajcman (2011), nenhuma organização é monolítica, sempre há espaço dentro das estruturas que as pessoas podem usar para criar significado e dignidade em sua vida de trabalho. Organizações são sistemas sociais dinâmicos, repletas de forças contraditórias que moldam seus arranjos.

As organizações se diferenciam entre si pelas suas “maneiras de fazer". Certeau (2008) diz que essas "maneiras de fazer" evidenciam as práticas cotidianas das quais seus atores se apropriam e criam um ambiente de "funcionamentos diferentes e interferentes", instauram a pluralidade e a criatividade, e são justamente essas maneiras de fazer nas pequenas empresas que as tornam tão singulares. Nesses ambientes, as práticas do dia-a-dia conduzem o fazer do 
gestor, que precisa se habituar a atuar em uma realidade em que o cotidiano se inventa, se modifica a cada dia. É no meio organizacional característico de pequenas empresas que se percebe um distanciamento entre "os quadros utópicos", teóricos, das maneiras de fazer e das "práticas efetivas e cotidianas": uma "disparidade entre os espetáculos de estratégias globais e a opaca realidade de táticas locais" (CERTEAU, 2008, p. 51).

O ramo funerário, mais especificamente, se caracteriza por ser formado, predominantemente, por empresas de pequeno porte. Dessa forma, empresas do ramo precisam desenvolver práticas de gestão que abarquem as especificidades do campo e que englobem, também, questões relacionadas à sensibilidade no desenvolvimento diário do trabalho, por estarem inseridas em um meio permeado pela dor da perda, incertezas e fragilidades dos clientes. O trabalho em funerárias exige a observância de preceitos éticos, como respeitabilidade, decência, honestidade, proteção à intimidade, cordialidade, respeito, entre outros (Código de Ética e Auto-Regulamentação do Setor Funerário).

Para Sá e Azevedo (2010, p. 2350), em trabalhos que estão relacionados à área da saúde e, aqui, podemos fazer associação com trabalhos que envolvem o enfrentamento com a morte, "a responsabilidade para com o outro é a essência do cuidado e também da gestão". Para as autoras, trata-se de um trabalho intersubjetivo, baseado na "intervenção de um sujeito sobre o outro, em suas experiências de vida, prazer, dor, sofrimento e morte". No trabalho realizado no ramo funerário, especialmente para os indivíduos que exercem funções em que há um contato direto com o cliente (gerentes, agentes funerários, cerimonialistas, maquiadores necrotéricos) esses aspectos são fundamentais: prestar um bom atendimento envolve usar suas experiências próprias, suas percepções sobre sofrimento, dor, morte, para a condução das atividades, transformando o ambiente de trabalho em um local que, apesar de estar cercado por uma atmosfera de tristeza, também pode propiciar trocas positivas, consoladoras, aliviando o peso que a morte traz.

Nesse sentido, torna-se importante olhar para essas relações, que são relações com os outros, para com os outros, envolvendo o trabalho, seu contexto, e os afetos com ele relacionados, o que remete agora discutir brevemente a questão da subjetividade.

\subsection{SUBJETIVIDADE E TRABALHO}

A construção da subjetividade é, cada vez mais, atravessada por diversas instâncias biopsicossociais. A lente desse estudo, no entanto, limita-se a observar o modo como esse

REAd | Porto Alegre - Vol. 23 - No Especial - Dezembro 2017 - p. 188-209 
trabalhador funerário vivencia a rotina de trabalho convivendo com a morte. Então, para tentar compreender os processos de subjetivação por quais passam os trabalhadores funerários no exercício do seu ofício, partiremos dos pensamentos de Castel (1998) acerca do trabalho. Para o autor, o trabalho é referência também psicológica, social, cultural, além de econômica, sendo através do trabalho estabelecidos processos integrativos entre sociedade e trabalhadores.

Nessa linha, Nardi et al. (2002) concordam que a subjetividade também se constitui na relação ser humano e trabalho em um processo de contínuas transformações. Os autores compreendem a subjetividade como resultante dos processos de interação entre indivíduos e sociedade, isto é, da forma como o sujeito constrói-se e é construído na trama do social.

Segundo Silveira (2006), o ser humano, no exercício do seu trabalho, pela análise da subjetividade e trabalho, passa a ser visto como sujeito, construindo sentidos singulares na sua relação com os modos de produção. Como sujeitos, constroem e reconstroem, em um eterno vir a ser e podendo ser de infinitas formas. Nesse sentido, fazendo referência a Deleuze (1986) e Guattari e Rolnik (1986), a produção de subjetividade constitui matéria prima de toda e qualquer produção (NARDI et al., 2002).

Para o percurso reflexivo a que nos propomos, nos aliaremos a uma lógica de produção de subjetividade, com destaque para o seu caráter processual e produtivo (GUATARRI, 1992). Dessa forma, recupera-se a noção de subjetividade compreendida como "não sendo passível de totalização ou de centralização no indivíduo" (GUATTARI; ROLNIK, 1996, p. 31). Disso decorre que a subjetividade emerge de uma produção incessante que acontece a partir dos encontros que vivemos com o outro, que também pode ser compreendido como um outro social, enfim tudo aquilo que produz efeito nos corpos e nas maneiras de viver (MANSANO, 2009). Resumidamente, entende-se a subjetividade como algo produzido por instâncias individuais, coletivas e institucionais (GUATARRI, 1992).

Em sequência, pensando em subjetividade e trabalho, conforme Nardi et al. (2002, p. 304), “os campos 'subjetividade e trabalho' constroem-se, portanto, no tensionamento entre as dicotomias indivíduo-coletivo e objetivo-subjetivo, interior-exterior”. Segundo os autores, refletir acerca da subjetividade e do trabalho remete-nos a pensar nas diversas formas de relação do ser humano com o trabalho, nos diversos tipos de significados e reações que apresenta diante do percebido e vivenciado, tanto podendo adotar posturas de conformação dos modos de agir, pensar e sentir, como através das resistências transgressoras ou de mobilização coletiva, de discussões nos espaços públicos e espontâneos de decisões com 
outros trabalhadores, para apontarem disfunções, para transformarem o que é gerador de sofrimento no trabalho e buscar o prazer na atividade laborativa.

Entende-se, assim, o trabalhador enquanto sujeito, não sendo um simples reprodutor de tarefas, mas aquele que constrói também seu espaço, os sentidos, as formas de fazer, sendo capaz de interferir nas orientações que regem o trabalho e ajustá-las às necessidades e ao contexto. Ao assim conceber o trabalhador, compreende-se, como aponta Silva (2008, p.111), que as atividades de trabalho são, muitas vezes, reformuladas ou até reinventadas, e, "consequentemente, apropriadas por sujeitos que renormalizam o seu meio e, na medida do possível, singularizam seus atos de trabalho de acordo com os seus próprios usos corporais, subjetivos, valorativos e simbólicos”. Além disso, a gestão em pequenas empresas, via de regra, apresenta-se com relações mais próximas entre as pessoas, em seus contextos específicos, onde são postos em cena laços afetivos adquiridos e vivências constituídas cotidianamente, em espaços ocupados pelos sujeitos.

\section{DO CAMPO DE PESQUISA}

A pesquisa foi realizada em uma funerária situada na cidade de Porto Alegre. Trata-se de uma empresa de pequeno porte, há 30 anos no mercado. A empresa oferece serviços relacionados à cremação, sepultamento, encaminhamento e organização de documentação, preparação de corpo, cerimonial de despedida, participação de falecimento, missa de $7^{\circ}$ dia e translado de corpo.

Conta com um quadro funcional composto por 21 pessoas, divididos nas seguintes funções: auxiliar administrativo (5 funcionários), auxiliar de agente funerário (3 funcionários), agente funerário ( 8 funcionários), gerente (3 funcionários), auxiliar de serviços gerais (1 funcionário), cerimonialista (1 funcionário), além de prestadores de serviço no ramo de maquiagem, preparação de corpo, floricultura e marketing. Além disto, fazem parte da estrutura 4 sócios e 2 diretores administrativos.

O quadro funcional é predominantemente masculino. O grupo de plantão é formado por 1 gerente, 2 agentes funerários e 1 auxiliar de agente funerário, em plantão de $12 \mathrm{~h}$ x $24 \mathrm{~h}$. Um grupo trabalha das $8 \mathrm{~h}$ às $20 \mathrm{~h}$. Este mesmo grupo volta a trabalhar no plantão das $20 \mathrm{~h}$ às $8 \mathrm{~h}$ do dia seguinte. Desta forma, todos os funcionários da área comercial trabalham todos os dias da semana, não há esquema de folgas. O período de descanso vai das $8 \mathrm{~h}$ de um dia até às 20h do dia seguinte. Não há divisão entre turnos diurno e noturno, todos trabalham em ambos 
turnos, de acordo com seu plantão.

A maquiadora necrotérica, embora prestadora de serviço, trabalha com dedicação de $24 \mathrm{~h}$ por dia, todos os dias da semana, sendo convocada a trabalhar sempre que o serviço de maquiagem for solicitado na empresa. A área administrativa, por sua vez, trabalha em regime de 40 horas semanais, de segunda a sexta-feira, em horário comercial.

\section{PERCURSO METODOLÓGICO}

Esse estudo é do tipo qualitativo. Acompanhamos a rotina de 4 agentes funerários, 1 diretor de plantão, 1 gerente administrativo, e 1 maquiadora necrotérica, em seu contexto de trabalho - a funerária já apresentada na seção anterior.

Para a coleta de dados utilizaram-se técnicas etnográficas para o acompanhamento do cotidiano dos pesquisados, como observação no local, entrevistas, conversas informais e diário de campo. O método etnográfico consiste no "levantamento de todos os dados possíveis de uma determinada comunidade com a finalidade de conhecer o estilo de vida ou a cultura específica da mesma" (CAVEDON, 2003, p. 143). Considera-se o estudo, entretanto, como uma experiência etnográfica e não como uma etnografia, na medida em que o tempo de imersão dos pesquisadores não se alongou como seria o desejado.

A primeira etapa da pesquisa foi a de observação, que é "o ato de perceber as atividades e os inter-relacionamentos das pessoas no cenário de campo" (ANGROSINO, 2009, p. 56). O processo de observação iniciou de forma não participante, com as pesquisadoras observando o ambiente sem interação com os funcionários da empresa, para compreender a dinâmica do trabalho e a rotina das atividades, considerando que "uma fase exploratória é, assim, essencial para o desenrolar ulterior da pesquisa" (VALLADARES, 2007, p. 153).

Após, partiu-se para o processo de observação participante, com a interação com os funcionários, estabelecendo-se uma relação mais ativa em relação à prática de observação, pois a "a observação participante implica saber ouvir, escutar, ver, fazer uso de todos os sentidos. É preciso aprender quando perguntar e quando não perguntar, assim como que perguntas fazer na hora certa" (VALLADARES, 2007, p. 154). Nesta etapa, todos os participantes da pesquisa já tinham conhecimento de pesquisa e de nosso papel dentro da empresa. Preliminarmente, nas primeiras visitas, foram priorizadas conversas informais, com o intuito de promover uma aproximação com os funcionários e estabelecer um vínculo menos

REAd | Porto Alegre - Vol. 23 - No Especial - Dezembro 2017 - p. 188-209 
formal entre as pesquisadoras e os pesquisados. As interações foram registradas em um diário de campo, com vistas a orientar a análise dos dados.

$\mathrm{Na}$ sequência, seguiu-se para as entrevistas, gravadas em áudio, totalizando-se sete horas. Nesta etapa, a colaboração do gerente administrativo foi essencial, pois ele serviu como informante, indicando as pessoas para falar sobre determinado assunto, liberando-as de suas atividades para realizar as entrevistas, e nos orientando sobre quais atividades poderíamos participar e observar (não nos foi permitido, por exemplo, o acompanhamento de uma venda, por tratar-se de um momento bastante delicado para os clientes, e foi considerado que a presença das pesquisadoras neste momento, observando e fazendo anotações, não seria adequada). Após, as entrevistas foram transcritas para fins de análise.

A interpretação dos dados foi realizada por meio de análise de conteúdo (MINAYO, 2010). Os achados foram agrupados em quatro categorias que são permeáveis e complementares entre si, e relacionadas ao processo de subjetivação - unidade de análise do estudo - do fazer/saber diante da morte: 1) redimensionando as certezas; 2) os saberes no/do trabalho frente a ressignificação da morte; 3) ser trabalhador atravessado pela representação da morte em sociedade; e 4) gestão se configurando no contexto da morte. Vale ressaltar que categorias aqui apresentadas se entrecruzam em vários momentos, uma vez que esses aspectos dizem respeito a um complexo arcabouço de caraterísticas nessa ressignificação de vida, de morte e de estabelecimento de práticas de trabalho e de gestão de pessoas na cotidianidade. Dessa forma, julgamos que a categorização adotada serve como mote de apresentação dos elementos que emergiram após a realização dos procedimentos de coleta de dados escolhidos para esse estudo.

\section{A MORTE SE CONSTITUINDO NO CAMPO DE TRABALHO}

A primeira categoria, redimensionando as certezas, relaciona-se com aspectos religiosos, educacionais, que orientam a construção subjetiva do trabalhador a partir da prática que realizam: "Depois que eu vim pra cá, passei a ser espírita. Não acredito mais que tudo acabe ali".

Nota-se, assim, que o primeiro fator fundamental para compreendermos a imersão desses sujeitos no trabalho passa pelo processo de redimensionamento da percepção da morte. Isso ocorre quando o trabalhador pensa na possibilidade de existirem outras vidas além dessa ou, ainda, evoca novos cultos religiosos. O que ocorre é que para esse trabalho na funerária, 
os atores vão constituindo sua subjetividade, com expuseram Nardi et al. (2004), a partir do processo de profundas transformações necessárias já no primeiro contato com o campo. Sobre essa questão, sugere-se que o trabalhador, ao repensar a existência de outras vidas, tenta atenuar a certeza da finitude materializada diariamente a partir do contato com o corpo morto/sem vida.

A relevância dessa percepção para a reflexão proposta nesse estudo se relaciona com o fato de que o mesmo trabalhador, se integrante de outra ambiência de trabalho, a qual não incitasse a convivência com a morte, muito provavelmente não necessitaria evocar questões religiosas para melhor relacionar-se com seu objeto de trabalho. Nesse ponto, recupera-se Caputo (2008) que, ao caracterizar a morte pelo mistério, pela incerteza e, consequentemente, pelo medo daquilo que não se conhece, ilustra essa busca de novos significados provocada em um primeiro contato com um trabalho que se desenvolve em interface com a morte.

Ainda nesse escopo, apresenta-se o então necessário desenvolvimento de uma percepção de naturalidade diante da presença da morte: "Quem vem e não consegue entender a morte como uma parte da vida, olhando como uma fase natural da vida, vai embora, não aguenta", conforme depoimento do gerente com relação ao primeiro contato dos candidatos com o processo de trabalho permeado pela morte. Verifica-se, então, a ocorrência de um processo de naturalização do fenômeno nesses ambientes.

Essa naturalização, na concepção dos funcionários, é desenvolvida de forma particular em cada um, relacionando-se com experiências pregressas: "Depende do que cada um viveu... um colega perdeu uma filha quando ainda era criança, então a gente nota que quando chega criança ele fica diferente do que nos demais casos". Desse modo, sugere-se que naturalizar a morte passa pela construção de um novo sentido para a vida, novos modos de subjetivação, uma vez que muitos relatam trabalhar na empresa há anos e que não gostariam de trabalhar em outro segmento.

Observa-se que as histórias de vida, assim como as de morte, envolvendo tragédias ou não, assumem um caráter coletivo bastante importante nesse grupo. Acabam por se constituírem como formas de desenvolver uma atenção maior ao outro, seja entre colegas seja em relação aos clientes. O que seria dor, transforma-se em uma forma construtiva de se relacionar. Essas histórias, além de terem uma função social, podem ser entendidas enquanto constitutivas de uma fundamental função psíquica.

Além disso, nesse contexto, há também redimensionamento de certezas com relação à reinvenção de si e do próprio sentido do trabalho e da vida: “Chega um momento que isso dá

REAd | Porto Alegre - Vol. 23 - No Especial - Dezembro 2017 - p. 188-209 
sentido a toda a nossa vida, essa parte, a do trabalho, ela invade as outras, você preparar alguém para o momento final, você tirar um sorriso do rosto dos familiares, faz a diferença, nos mantém aqui e sempre pensando no sentido da vida, sabe. Vou te falar, só sairia daqui pra ganhar mais. Estou aqui desde 1980, já trabalhei em outros empregos, mas hoje larguei todos e fiquei só nesse".

Com isso, morte se transforma em vida, dor em criação, revelando a organização enquanto espaço de contradições, enquanto espaço dinâmico, ressaltando-se nesse espaço o papel ativo das pessoas nas organizações. Outra categoria que emerge a partir da coleta de dados, os saberes do/no trabalho frente à ressignificação da morte, diz respeito à preparação para o trabalho, que vai além do treinamento que recebem na contratação, uma vez que as próprias rotinas e técnicas de trabalho também contemplam a dimensão subjetiva de se trabalhar com a morte. Com relação à ordenação do corpo, por exemplo, a maquiadora relata que foram as técnicas de preenchimento e pintura que desenvolveu praticando, que tornaram seu trabalho único: "Eu já fiz cursos, mas quando vinha alguém com câncer no rosto, ou acidente, eu desenvolvi técnicas de preenchimento com talco, com base, fica perfeito".

Nesse caminho, constata-se também que é no atendimento às famílias que o conhecimento do agente funerário se consagra: "Dependendo do tipo de morte, tu recebe o familiar com postura diferente, vamos treinando o nosso olhar. Quando entra a família, eu já sei se morreu de câncer ou de acidente. Isso não tem curso que ensine”.

A doença oncológica assume uma dimensão particular na gestão do luto, pois o familiar, comumente, traz um desgaste do período da doença e a morte significa libertação da dor. Para essas percepções que emergem do cotidiano do trabalho na funerária, é o próprio agente, na relação pessoal com o seu fazer, que vai aprimorando esse modo de trabalhar.

Vemos, assim, que as técnicas de trabalho, do ponto de vista do trabalhador, foram sendo aprimoradas na prática, mas que essas também são atravessadas pela ressignificação da morte, o que dá sentido ainda mais singular a essa rotina de trabalho. Para além disso, o trabalhador relata que a própria maneira de se portar ao receber o familiar, vai sendo incorporada como uma prática concreta, à maneira que, progressivamente ele vai sendo exposto às mais diferentes situações de contato com diferentes famílias enlutadas. Dessa maneira, conforme Nardi et al. (2004), temos aí o tensionamento entre as dicotomias indivíduo-coletivo, objetivo-subjetivo e interior-exterior, remetendo a novos processos de subjetivação no exercício do trabalho a partir dessas reações relacionais com o percebido e vivenciado. Tal tensionamento, inclusive, levou o trabalhador a adotar novas posturas - mais

REAd | Porto Alegre - Vol. 23 - No Especial - Dezembro 2017 - p. 188-209 
profissionais e maduras que são reconhecidas no ambiente de trabalho.

A terceira categoria, a qual chamamos ser trabalhador atravessado pela representação da morte em sociedade discute aspectos sociais sob duas óticas complementares. A primeira pressupõe a relação desses funcionários com o ambiente social externo, por exemplo, a forma como famílias e amigos observam esse trabalho: "Primeiro as pessoas tinham certo receio de a gente trabalhar com morto, depois foram acostumando...”, ou "No início eu maquiava os vivos e os mortos, as pessoas passaram a me questionar sobre isso e eu sempre dizia que tinha uma maleta de maquiagem para os vivos, outra para os mortos. Lá fora há toda essa coisa em torno da morte”.

Nesse sentido, os trabalhadores reconhecem o estranhamento da sociedade, justificando o tema ser visto como tabu. A outra ótica se relaciona ao ambiente interno, como as relações interpessoais, bem como as práticas de gestão de pessoas. Quanto às relações interpessoais, os trabalhadores disseram que o clima de convivência é visto como agradável, alegre, para fazer frente à singularidade do trabalho: "Se vocês esperam ver um clima triste, quieto, aqui, não vão ver. Somos uma família, a empresa é pequena, todo mundo se conhece, vivemos rindo, contando piada ali na salinha de convivência. Se não for assim não dá, vamos embora muito carregados".

Do ponto de vista social, a estranheza provocada no círculo social do trabalhador (família, amigos), após a imersão do mesmo no campo de trabalho da morte, pode ser repensada tanto a partir das ideias de Caputo (2008), apresentadas no início dessa seção, e que remetem às incertezas que circundam o fenômeno da morte, como também às ideias de Morin (1970) ao caracterizar a relação do homem com o luto, o qual exprime socialmente a inadaptação à morte. Historicamente, a morte, como dito, tornou-se um tabu na vida em sociedade e, com isso, o trabalhador acaba tendo que inventar formas de se relacionar com esse inevitável momento de vida.

Observa-se, assim, a importância do compartilhar espaços e situações comuns, bem como da construção de laços "de família", fatores que propiciam um bom clima de conversas e brincadeiras. Esses aspectos destacam um espaço de humanização da convivência, permitindo amenizar a rotina e o pesar da convivência com a morte.

Ainda, pode-se identificar outra categoria relacionada, por sua vez, com a organização do trabalho permeado pela morte, a qual chamamos de gestão se configurando no contexto da morte. Nesse segmento, destaca-se a importância da socialização das experiências: "Aquele que vende melhor, porque aqui é um comércio...bom, a gente ensina um pro outro, o 
que recebe melhor a família também vai explicando e assim vamos criando o nosso jeito de fazer". A empresa familiar legitima o espaço de construção em grupo, porque fomenta esse vínculo para que os funcionários criem uma identidade de trabalho, um espaço de convivência (CERTEAU, 2008), promovendo retenção de pessoas. Isso se evidencia na fala do diretor de plantão: "Hoje as pessoas que chegam aqui para trabalhar, participam de seleção, como em outras empresas, mas para permanecer depende de uma série de fatores e acreditamos que esse desenvolvimento pessoal e amadurecimento frente ao tema da morte, alcançado nessa dimensão de grupo, seja muito importante para continuarem aqui”.

Os trabalhadores encontram, assim, espaços para união, seja pelas afinidades que acabam desenvolvendo ou como forma para somarem força para enfrentar o dia-a-dia do trabalho. Ainda nesse escopo, vemos as práticas de gestão que vão se configurando na rotina de trabalho da pequena empresa. O profissional de Recursos Humanos entrevistado relata que as pessoas chegam para a seleção, na maioria das vezes, por indicação, dada a singularidade da prática de trabalho. O tempo médio de permanência na empresa é de cinco anos, e o trabalhador relaciona esse tempo elevado de permanência com o fato de a empresa oferecer salários em dia e ter plano de carreira.

O mesmo profissional apresenta os pré-requisitos para o recrutamento na pequena empresa estudada, de forma bastante informal: "Tem que ter boa caligrafia, não pode ter muita tatuagem, boa aparência, ensino médio completo e, depois, claro, observamos de que forma ele vai reagir trabalhando com esse ramo da morte". Sobre essa forma de reagir, que se dá desde os primeiros dias no trabalho, o entrevistado relata que muito aprendeu a partir das próprias vivencias no grupo: "A gente percebe hoje que é o próprio grupo e as características do grupo que dão o tom pra selecionarmos as pessoas".

Já com relação ao treinamento, o profissional disse que os funcionários mais antigos ensinam aos mais novos; com relação aos cargos, ele coloca: "a pessoa entra na empresa como auxiliar de agente funerário, depois agente funerário, depois torna-se gerente - que é o chefe do turno. O primeiro atendimento é sempre do agente", entendendo que essa possibilidade de crescer dentro da empresa é algo valorizado pelos funcionários. A forma de fazer gestão de pessoas, então, mistura-se com os fazeres e com as vivências de cada um dos profissionais, constituindo-se e sendo construída nessas relações.

Deste modo, a partir das proposições de Certeau (2008), podemos compreender essa agência funerária como uma organização que vai construindo técnicas próprias, seja de seleção ou retenção de pessoas, de acordo com a própria capacidade de o profissional 
relacionar-se com a especificidade de se trabalhar com a morte. Assim, os achados demonstraram afinidade com o autor, uma vez que estas "maneiras de fazer" evidenciam as práticas cotidianas das quais seus atores se apropriam, as modificam, e criam um ambiente de "funcionamentos diferentes e interferentes", instaurando a pluralidade e a criatividade (como o desenvolvimento de uma massa própria para maquiagem dos mortos, durante o desenvolvimento do trabalho), e são justamente estas maneiras de fazer nas pequenas empresas que as tornam tão singulares.

Por essa razão, as estratégias de vida e trabalho em um contexto de morte, bem como o fazer gestão de pessoas na empresa estudada, envolvendo desde a seleção, o preparo para o trabalho, a retenção e os cuidados nas relações entre as pessoas, são construídas na cotidianidade, ou seja, conforme Certeau (2008), em um espaço onde trabalhadores fazem a gestão do seu cotidiano e a si mesmos com seus próprios significados. Logo, as práticas de trabalho e de gestão de pessoas vão sendo constituídas com compartilhamento de experiências e de saberes, uma vez que serão atravessadas, diariamente, pelo conjunto de características heterogêneas de um grupo de trabalhadores que estão em constante processo de mudança e amadurecimento.

\section{CONSIDERAÇÕES FINAIS}

Finalizando, a partir da discussão trazida com as categorias apresentadas, tem-se que na análise das relações interpessoais, entre os profissionais e os colegas que convivem e trabalham na funerária, em um contexto social, talvez resida o ponto fundamental que nos norteou na condução reflexiva desse estudo.

Para além da óbvia rotina atravessada pela presença da morte, como já discutido, percebe-se que é no enfrentamento subjetivo e no compartilhamento dessas experiências vividas na execução particular de cada tarefa, de acordo com as diferentes funções de transporte, maquiagem, venda, acolhimento à família enlutada, na rotina de trabalho da agência funerária estudada, que emergem os processos de intersubjetivações acerca do fenômeno de se trabalhar com a morte.

Ainda, entende-se que a partir desses processos vão sendo construídas práticas de trabalho, de gestão de pessoas, que aqui foram analisadas tomando duas caracterizações que singularizaram esses processos: a morte e a pequena empresa.

Dessa forma, o presente estudo objetivou compreender como, em local onde o trabalho

REAd | Porto Alegre - Vol. 23 - No Especial - Dezembro 2017 - p. 188-209 
exige enfrentamento com a morte, são pensadas e construídas práticas de trabalho e de gestão de pessoas, permeadas pela formação da subjetividade e enfrentamento com a morte.

De início, tem-se que o enfrentamento com a morte é um fator fundamental para compreender a relação dos trabalhadores funerários com o corpo sem vida. Mais especificamente, analisamos nos resultados a compreensão que o trabalhador passa a ter acerca do fato de trabalhar com a morte e como esse trabalho apresenta-se como referência não só econômica, mas também, psicológica, cultural e simbolicamente dominante para a discussão sobre os processos de integração da sociedade e dos trabalhadores (CASTEL,1998).

Vimos que, embora a empresa busque aliar suas estratégias de negócios com as experiências individuais e em grupo desses profissionais, não se pode considerar uma uniformização vertical da gestão, mas práticas horizontais que, intersubjetivadas, caracterizam, paulatinamente, seus modos de saber e fazer.

O ambiente organizacional passa a ser, em consonância com Certeau (2008), um espaço onde trabalhadores fazem a gestão do seu cotidiano e a si mesmos com seus próprios significados. Percebem-se espaços de contínua reconstrução do trabalho e do que se produz (não apenas de negócios), ou ainda do ser trabalhador naquele contexto. Com isso, olhamos para lógica do cotidiano do trabalho, em práticas que passam pela subjetivação dos fazeres diante da morte e do morrer.

Dessa forma, as práticas de gestão de pessoas e de trabalho na pequena empresa estudada, são pensadas e construídas coletivamente, no corpo social formado pelos trabalhadores, empresa e gestores. Dada a singularidade do trabalho que envolve vários processos de ressignificação de vida, de morte, de desenvolvimento de novas técnicas de manejo de corpos, de habilidades sociais diferenciadas para o acolhimento dos familiares, a empresa entende que somente se obterá êxito na proposta de atendimento e serviços oferecidos para os trâmites com os mortos, se forem assim estabelecidas as relações de trabalho.

Entende-se que essa compreensão acerca da prática de gestão de pessoas e de trabalho (CERTEAU, 2008), observada na empresa estudada, possa ser estendida a outras pequenas empresas, uma vez que as práticas de gestão de pessoas historicamente difundidas pelos manuais de Gestão, em sua maioria, foram desenvolvidas a partir do estudo de grandes organizações, com corpo social e objetivo econômico maiores e mais complexos.

Mesmo que haja uma singularidade provocada pelo fato de se trabalhar com a morte, $o$ presente estudo contribui para a reflexão de como se fazer gestão de pessoas em pequenas

REAd | Porto Alegre - Vol. 23 - No Especial - Dezembro 2017 - p. 188-209 
empresas, ao descortinar modos criar e de se relacionar no ambiente da funerária, que evidenciam práticas horizontais de organização do trabalho, centrada na riqueza das descobertas individuais dos atores envolvidos, bem como no compartilhamento dessas descobertas; promovendo, com isso, o uso da criatividade no desenvolvimento de inovações técnicas e melhores habilidades laborais.

Já a produção de subjetividade (GUATARRI, 1992; MANZANO, 2009) trabalho/morte emerge dessa produção incessante que acontece a partir dos encontros que vivemos com o outro, tal qual a experiência proporcionada pelo trabalho na funerária, que aí vai ser compreendida como o outro social, produzindo efeito nos corpos e nas maneiras de viver desses trabalhadores estudados.

Refletimos, também, sobre a forma como esses profissionais instituem modos de pensar e de agir, que permeia a organização do trabalho na funerária, como uma referência essencial para suas vidas (TITTONI, 1994). Assim, os modos de ser do sujeito, como observado nas categorias, não só delimitam as formas de expressão da subjetividade, como também pautam as formas de se fazer gestão de pessoas nessa empresa.

Destacamos, portanto, possibilidades de investigação a partir dessa abordagem, favorecendo um olhar diferenciado para a gestão de pessoas, valorizando espaços, maneiras de fazer, de fazer com. Valoriza-se o olhar para o trabalhador enquanto sujeito, como aquele que constrói também seu espaço, os sentidos, as formas de fazer, criar, reinventar, sendo capaz de interferir nas orientações que regem o trabalho e ajustá-las às necessidades e ao contexto.

\section{REFERÊNCIAS}

ABREDIF. Associação Brasileira de Empresas e Direitos Funerários. CEARF - Código de Ética e Auto Regulamentação do Setor Funerário. Fortaleza, CE, 10 de novembro de 1998. Disponível em: http://www.portalfunerariodobrasil.com.br/wpcontent/uploads/2014/06/ABREDIF.pdf. Acesso em: 9 ago. 2015.

ANGROSINO, M. Etnografia e observação participante. Porto Alegre: Artmed, 2009. ANVISA. Agência Nacional de Vigilância Sanitária. Referência Técnica para o Funcionamento de Estabelecimentos Funerários e Congêneres. Disponível em: http://portal.anvisa.gov.br/documents/33856/2054354/Refer\%C3\%AAncia+t\%C3\%A9cnica+ para+o+funcionamento+de+estabelecimentos+funer\%C3\%A1rios+e+cong\%C3\%AAneres/30

REAd | Porto Alegre - Vol. 23 - No Especial - Dezembro 2017 - p. 188-209 
2ffe07-3186-427d-93ab-062a7b311d81. Acesso em: 21 ago. 2015.

\section{BIANCHESSI, D. L. C. Trabalho, saúde e subjetividade na diversidade de um hospital} geral, público e universitário. 2006. 132 p. Dissertação (Mestrado em Psicologia) -

Programa de Pós-Graduação em Psicologia Social e Institucional, Universidade Federal do Rio Grande do Sul, Porto Alegre, 2006.

BIANCHESSI, D. L. C.; TITTONI, J. Trabalho, saúde e subjetividade sob o olhar dos trabalhadores administrativo-operacionais de um hospital geral, público e universitário. Physis, Rio de Janeiro, v. 19, n. 4, p. 969-988, 2009. Disponível em: http://www.scielo.br/pdf/physis/v19n4/v19n4a04.pdf . Acesso em: 24 ago. 2015.

CAPUTO, R. F. O homem e suas representações sobre a morte e o morrer: um percurso histórico. Revista Multidisciplinar da UNIESP: Saber Acadêmico, n.6, p.73-80, 2008. Disponível em: http://www.uniesp.provisorio.ws/revista/revista6/pdf/8.pdf. Acesso em: 19 ago. 2015.

CAVEDON, N. R. Antropologia para administradores. Porto Alegre: UFRGS, 2003. Modos de enfrentamento da morte violenta: a atuação dos servidores do Departamento de Criminalística do Instituto Geral de Perícias do Rio Grande do Sul. Revista de Administração Mackenzie, v. 12, n. 4, p. 75-104, 2011. Disponível em: http://www.scielo.br/pdf/ram/v12n4/v12n4a04.pdf. Acesso em: 2 ago. 2015. CERTEAU, M. de. A invenção do cotidiano: 1. Artes de fazer. Petrópolis: Vozes, 2008. COMBINATO, D. S.; QUEIROZ, M. de S. Morte: uma visão psicossocial. Estudos de Psicologia, v. 11, n. 2, p. 209-216, 2006. Disponível em: http://www.scielo.br/pdf/epsic/v11n2/a10v11n2.pdf. Acesso em: 19 ago. 2015. DAVEL, E.; VERGARA, S. C. Gestão com pessoas e subjetividade. São Paulo: Atlas, 2001.

EDWARDS, P.; WAJCMAN, J. The politics of working life. New York: Oxford University Press Inc., 2011.

GUATARRI, F. Caosmose: um novo paradigma estético. Tradução de Ana Lúcia de Oliveira e Lúcia Cláudia Leão. Rio de Janeiro: Ed. 34, 1992.

GUATTARI, F.; ROLNIK, S. Micropolítica: cartografias do desejo. Petrópolis: Vozes, 1996. HERVAL, R.; MENEZES, C. Passando dessa para melhor. Revista PUCRIO Digital, n. 27 , julho/dezembro 2008. Disponível em: http://puc-riodigital.com.puc-rio.br/media/7\%20\%20passando\%20dessa\%20pra\%20melhor.pdf. Acesso em: 17 ago. 2015. 
JUNQUILHO, G. S.; ALMEIDA, R. A. de; SILVA, A. R. L. da. As "artes do fazer" gestão na escola pública: uma proposta de estudo. Cad. EBAPE.BR, v. 10, n. 2, p. 329-356, 2012. Disponível em: http://www.scielo.br/pdf/cebape/v10n2/v10n2a06.pdf. Acesso em: 24 ago. 2015.

KOVACS, M. J.; VAICIUNAS, N; ALVES, E. G. R. Profissionais do Serviço Funerário e a Questão da Morte. Psicologia: Ciência e profissão, v. 34, n. 4, p. 940-954, 2014. Disponível em: < http://www.scielo.br/pdf/pcp/v34n4/1982-3703-pcp-34-4-0940.pdf>. Acesso em: 17 ago. 2015.

LEONE, N. M. C. P. G. As especificidades das pequenas e médias empresas. Revista de Administração, v. 34, n. 2, p. 91-94, 1999.

MANSANO, S. R. V. Sujeito, subjetividade e modos de subjetivação na contemporaneidade.

Revista de Psicologia da UNESP, v. 8, p. 110-117, 2009. Disponível em:

http://revpsico.assis.unesp.br/revpsico/index.php/revista/article/viewArticle/139/173.

Acesso em: 29 ago. 2015.

MINAYO, M. C. S. (Org.). Pesquisa social: teoria, método e criatividade. 29. ed. Petrópolis: Vozes, 2010.

MORIN, E. O homem e a morte. Tradução de João Guerreiro Boto e Adelino dos Santos Rodrigues. Lisboa: Europa-América, 1970 [1951].

NARDI, H. C. Saúde do trabalhador, subjetividade e interdisciplinaridade. MERLO, A. R.C. (Org.). Saúde e trabalho no Rio Grande do Sul: realidade, pesquisa e intervenção. Porto Alegre: UFRGS, 2004. p. 43-64.

NARDI, H. C.; TITTONI, J.; BERNARDES, J. Subjetividade e Trabalho. CATTANI, A. (Org.). Dicionário crítico sobre trabalho e tecnologia. 4. ed. Petrópolis: Vozes, 2002. p. 302-308.

NGUYEN, T.; BRYANT, S. A study of the formality of human resource management practices in small and medium-size enterprises in Vietnam. International Small Business Journal, v. 22, n. 6, p. 595-618, 2004. Disponível em:

http://journals.sagepub.com.ez45.periodicos.capes.gov.br/doi/pdf/10.1177/026624260404741 2. Acesso em: 15 ago. 2015.

SÁ, M. C.; AZEVEDO, C. S. Subjetividade e gestão: explorando as articulações psicossociais no trabalho gerencial e no trabalho em saúde. Ciência \& Saúde Coletiva, v.15, n.5, p. 23452354, 2010. Disponível em: http://www.scielo.br/pdf/csc/v15n5/v15n5a10.pdf. Acesso em: 17 ago. 2015.

REAd | Porto Alegre - Vol. 23 - No Especial - Dezembro 2017 - p. 188-209 
SHAHARIN, S. Exploring human resource (HR) practices in small medium-sized enterprises (SMEs) and firm performance. Dissertação (Mestrado em Business Studies) Department of Business Studies, Faculty of Economics and Business, University of Amsterdam, Amsterdam, 2012.

SILVA, C. A. F. A gestão de si na reinvenção das normas: práticas e subjetividade no trabalho. Saúde e Sociedade, v. 17, n. 4, p. 111-123, dez. 2008. Disponível em:

http://www.scielo.br/pdf/sausoc/v17n4/12.pdf. Acesso em: 23 ago. 2015.

SILVA, F. L. L.; ZAMBRONI-DE-SOUZA, P. C.; ARAÚJO, A. J. S. Análise das condições e da organização do trabalho dos necrotomistas. Psicologia em estudo, v. 19, n. 1, p. 81-91, 2014. Disponível em: http://www.scielo.br/pdf/pe/v19n1/09.pdf. Acesso em: 17 ago. 2015. SOUZA, K. C. C.; BOEMER, M. R. O significado do trabalho em funerárias sob a perspectiva do trabalhador. Saúde Sociedade, v. 7, n. 1, p. 27-52, 1998. Disponível em: http://www.scielo.br/pdf/sausoc/v7n1/03.pdf. Acesso em: 29 ago. 2015.

SPARROW, S. We don't need HR. Personnel Today, Reino Unido, 14 mar. 2006.

Disponível em: http://www.personneltoday.com/hr/we-dont-need-hr/. Acesso em: 18 nov. 2015.

TITTONI, J. Saúde mental, trabalho e outras reflexões sobre a economia solidária. MERLO, Á. R. C. (Org.). Saúde e trabalho no Rio Grande do Sul: realidade, pesquisa e intervenção. Porto Alegre: UFRGS, 2004. p. 65-93.

Subjetividade e trabalho. Porto Alegre: Ortiz, 1994.

VALLADARES, L. Os dez mandamentos da observação participante. Revista Brasileira de Ciências Socias, vol. 22, n. 63, p. 153-155, 2007. Disponível:

http://www.scielo.br/pdf/rbcsoc/v22n63/a12v2263.pdf. Acesso em: 21 ago. 2015.

VIGOTSKI, L. S. Teoria e método em psicologia. Tradução de Claudia Berliner. São Paulo: Martins Fontes, 1996. 